\title{
Reflection-impulsivity and script-action recall
}

\author{
HELEN SWANSON \\ University of Wisconsin Center-Manitowoc County, Manitowoc, Wisconsin \\ and \\ GARY SCHUMACHER \\ Ohio University, Athens, Ohio
}

(Francis S. Bellezza, Sponsor)

\begin{abstract}
Script-recall differences between reflective and impulsive subjects were investigated. Using the Bower, Black, and Turner (1979) methodology, it was found that reflective subjects recalled more stated actions than did impulsive subjects regardless of number of instantiations of scripts presented, indicating that cognitive style influences schematic information processing.
\end{abstract}

\begin{abstract}
"Script" is the term commonly used by cognitive psychologists to denote a specialized type of schema, or knowledge structure, wherein the various typical components of some routinized action (e.g., getting up in the morning) are stored in memory. Thus, for example, a "getting up in the morning" script may include putting on slippers, making toast and coffee for breakfast, brushing teeth, taking a shower, and putting on clothes for the day. Cognitive psychologists have attempted to examine the influence of previously established scripts on the storage and recall of new information. Thus, knowledge has been gained about such cognitive processes as the recognition and recall of unusual information presented in text material (Bellezza \& Bower, 1982) and the nature of inferences (e.g., Bower, Black \& Turner, 1979).

In Experiment 2 of Bellezza and Bower (1982), subjects recalled nouns embedded in previously studied script events, using either the scripts themselves or pegwords (which were paired with the target nouns during the learning phase) as recall cues. It was found that atypical nouns (i.e., ones which were inappropriate for a particular script) were recalled better in the pegword than in the script condition. The authors concluded that the pegword condition minimized interference from the subjects' previously established scripts, in which supposedly only typical nouns were stored.
\end{abstract}

Bower et al. (1979) tested whether subjects would incorrectly report during recall the presence of script actions that were purposely omitted from the script vignettes studied earlier. Some of the vignettes presented were based on the same underlying scripts, whereas others were

An abbreviated form of this paper was presented at Midwestern Psychological Association in Chicago, May, 1984. The authors wish to extend their appreciation to James Swanson for his help in scoring the data, and to Francis Bellezza for his helpful comments. Requests for reprints may be sent to: $\mathrm{H}$. Swanson, Department of Psychology, University of Wisconsin Center-Manitowoc County, Manitowoc, WI 54220. single instantiations (i.e., versions) of a script. It was expected that the frequency of recall errors would increase when the number of instantiations of the same underlying script was increased, due to greater interference. Recalled actions were categorized into three types: stated, unstated, and other script actions. "Stated actions" actually appeared in the vignette being recalled; "unstated actions" did not. "Other actions" were defined primarily as summarizations of lower-level script actions appearing in the vignettes (e.g., "boiled water" in place of "filled pot with water, placed pot on stove"). Results indicated that stated script actions were recalled two to three times more frequently than were unstated script actions, which, in turn, were recalled more frequently than were other actions. However, as predicted, the percentage of unstated script actions did increase significantly when two script versions, as opposed to one, were studied, although the increase leveled off at this point.

As was the case in both studies just reported, most investigations in this area have focused exclusively on the influence of script variables on recall performance, and have excluded subject variables. However, it may be that certain personality characteristics, such as cognitive style, may also play an important role in schematic information processing. Of particular interest in the present investigation was the dimension of reflection-impulsivity.

Kagan and Kogan (1970) define this cognitive style as "the degree to which the subject reflects on the validity of his solution hypothesis in problems that contain response uncertainty" (p. 1309). Messer (1976) uses a similar definition: "Reflection-impulsivity describes the tendency to reflect on the validity of problem-solving under a very special condition, namely, when several possible alternatives are available and there is some uncertainty over which one is the most appropriate' (p. 1026).

Since these definitions rely centrally on one of the same terms they are meant to define (i.e., reflection), it can be argued that somewhat circular reasoning is being ap- 
plied here. Exactly what does one do when one reflects? Inferring from the above definitions, we define reflection as judging whether a particular idea is a suitable solution to the problem at hand. Apparently, a reflective person would take into consideration more aspects or details of a particular idea as they relate to the problem, and would also compare this idea to more alternative ideas than would an impulsive person. Messer (1976) touches upon this point by stating that reflectives spend more time evaluating their hypotheses and acquire their information more systematically than do impulsives.

If, as Kagan and Kogan (1970) and Messer (1976) seem to suggest, reflectives do possess superior encoding and retrieval skills, it may be that reflective individuals fare better overall in schematic recall experiments. In order to test this possibility, we first identified subjects as reflective or impulsive, then replicated Experiment 3 of Bower et al. (1979) (described earlier). Because of their supposed superior information processing skills, reflectives were expected to recall more stated script actions than were impulsives. Conversely, due to less adequate processing, impulsives were expected to recall more unstated actions. Since the same cognitive style would function whether one, two, or three instantiations of the underlying scripts were presented, these predictions were expected to hold true regardless of the number of instantiations presented.

\section{METHOD}

\section{Subjects}

Forty-two students who were enrolled in psychology courses at Ohio University served as subjects. A small number of additional subjects were eliminated from the study because they did not classify as either reflective or impulsive. All participants received course credit for participation.

\section{Stimuli}

Kagan's Matching Familiar Figures Test (MFFT; 1965), adult version, was administered to assess each subject's relative degree of reflection-impulsivity. A narrative that was unrelated to the experimental stories was read by the subjects for $10 \mathrm{~min}$. Later recall of this material served as an interpolated task. The experimental text material employed was identical to that used by Bower et al. (1979). This material consisted of 27 stories (with titles), each of which was 7-8 lines in length. These stories contained about 20 actions and included three versions of each of nine basic scripts; for example, "The Movie," "The Play," and "The Concert" were created from the "Performance" script.

Each subject received a booklet composed of 18 stories, presented in a randomized order. In order to check for story effects, we randomly selected 18 stories from the total pool of 27 three different times, thus forming three separate "script groups." The only qualification to the random story-selection process was that for any given script, one third of the subjects read all three story versions, one third read two randomly selected versions, and one third read only one version, again randomly selected. Thus, each script group was presented three versions of three scripts, two versions of three other scripts, and one version of the remaining three scripts.

All three stories from each script were constructed so that the beginnings and endings gave the same type of information across stories (e.g. the character was feeling poorly at the beginning of the "Health Professional" script stories), but exact wording was story-specific (e.g., Carol had a bad toothache in "The Dentist" story, and Peggy had a bad pain in her back in "The Chiropractor" story). However, the actions stated in the middle lines of each of these stories, despite being generated from the same script, were not repeated in the other stories of the set.

A stopwatch was used to measure subjects' reaction times during the MFFT, and to time the various segments of the script session.

\section{Procedure}

Testing took place in a small room in an experimental research building on campus. The subjects were individually administered the MFFT. A median split was used to determine the subjects' relative degrees of reflection-impulsivity. In this sample, the mean response latency of the reflectives was $70.72 \mathrm{sec}$, and the mean number of errors was 3.57; for the impulsives, these figures were 27.23 and 13.4, respectively. (Subjects falling above the mean on one variable and below the mean on the other [i.e., fast-accurate or slow-inaccurate] were eliminated from the study, and the means were recalculated.)

Subjects then were asked to return to the same room on a subsequent date during the following week for further testing. For this part of the experiment, subjects were tested in small groups, all of which received the same basic instructions.

In order to place subjects in an appropriate frame of mind for the experimental task and to provide material for an upcoming interpolated task, we had subjects read for $10 \mathrm{~min}$ the narrative described earlier. They then were given the following instructions: "Within this booklet you will find 18 short stories, complete with titles. For the next $10 \mathrm{~min}$, I would like you to carefully read and study these stories. Any questions? You may begin." When $10 \mathrm{~min}$ had passed, the subjects were asked (as an interporlated task) to reproduce for $20 \mathrm{~min}$ as much as possible of the narrative they had read at the beginning of the experiment.

Each subject was then given 18 blank sheets of paper, one for each of the 18 stories they were asked to recall. They were given $1 \mathrm{~min}$ to recall each of the stories, reproducing them verbatim when possible, or recalling the gist of actions not remembered verbatim. As a cue, the experimenter read aloud the title of each story to be recalled at the beginning of each successive minute.

\section{RESULTS}

A $2 \times 3 \times 3$ mixed-design ANOVA was carried out on each of the three dependent measures: reflectionimpulsivity (between subjects), number of instantiations read per script (within subjects), and group (between subjects; the randomizing variable), respectively. The three dependent variables were stated, unstated, and other script actions recalled.

$T$ tests were also calculated in order to determine whether reflectives differed from impulsives with regard to their overall verbal fluidity and ability. Verbal fluidity was measured by the number of script actions recalled, regardless of their categorization. A measure of the subjects' verbal ability was obtained from their college entrance examination verbal-aptitude scores (either SAT or ACT). These were transformed to $z$ scores for further analysis.

No difference was found between the mean number of total actions recalled by the two groups, or between the two groups' mean verbal college entrance examination scores $[t(40)<1, p>.05$ for both], indicating similarity in overall verbal fluidity and ability.

As expected, reflectives recalled more stated script actions than did impulsives $[F(1,41)=6.92, p<.02]$, regardless of number of script instantiations (see Table 1 ). Impulsives did recall more unstated actions than did reflec- 
Table 1

Mean Number of Stated Actions Recalled by Reflectives and Impulsives with One, Two, and Three Instantiations of Underlying Scripts

\begin{tabular}{ccc}
\hline $\begin{array}{c}\text { Number of } \\
\text { Instantiations }\end{array}$ & Reflectives & Impulsives \\
\hline 1 & 28 & 21 \\
2 & 25.43 & 19.96 \\
3 & 24.48 & 19.24 \\
Total & 77.91 & 60.96 \\
\hline
\end{tabular}

Table 2

Mean Number of Unstated Actions Recalled by Reflectives and Impulsives with One, Two, and Three Instantiations of Underlying Scripts

\begin{tabular}{ccc}
\hline $\begin{array}{c}\text { Number of } \\
\text { Instantiations }\end{array}$ & Reflectives & Impulsives \\
\hline 1 & 1.90 & 1.86 \\
2 & 1.48 & 2.17 \\
3 & 1.95 & 2.81 \\
Total & 5.33 & 6.84 \\
\hline
\end{tabular}

tives, although this is nonsignificant $[F(1,41)=2.05, p<$ .17] (see Table 2). The groups did not differ on the mean number of actions classified as "other" that they recalled.

With regard to the instantiation variable, number of instantiations of underlying scripts did affect recall performance, but only on stated script actions $[F(2,41)=3.45$, $p<.04]$. A Tukey test of the main effect of this variable on stated script actions revealed that more stated script actions were recalled when one versus three script instantiations were presented. As predicted, no overall interactions between number of instantiations and reflectionimpulsivity were found for any of the dependent variables.

\section{DISCUSSION}

Reflection-impulsivity affected schematic information recall: reflectives demonstrated greater accuracy. This indicates that in situations in which reliance upon schematic memory is necessary (e.g., accounts of common situations), reflectives probably fare better. This differential performance cannot be attributed to differences in verbal fluidity and ability, since in this sample the two groups were equivalent in these respects. It may be that reflectives have adopted more successful information storage or retrieval strategies, or both. Future research should examine the relative contribution of each of these components, thus more clearly indicating the weaknesses of impulsives on this type of task.

Although the impulsives did not, as predicted, recall more unstated script actions overall than did reflectives, results were in the expected direction. Thus, research in this domain may yet prove fruitful as well.

The present findings have important implications for researchers interested in formulating a comprehensive model of scripts in relation to memory. Currently, script models focus predominantly on content or processing variables, with little if any consideration of subject variables. For example, Schank and Abelson (1977) place major importance on the degree of typicality of script events, the use of inferences when encountering incomplete scripts, and the distracting effects of script interaction (i.e., the intermingling of two or more scripts). The only attention which has been paid to subject variables deals with a distinction between personal and situation-based scripts. Personal scripts involve actions that are familiar to certain individuals (e.g., swindling) but may be unrecognized (due to lack of experience) by others present. Situationbased scripts, on the other hand, are acknowledged and understood by all of those involved in carrying them out. Thus, Schank and Abelson (1977) do pay some attention to subject variation in script processing, but only in terms of individual experience, not personality.

More recently, Graesser and Nakamura (1982) have delineated a "Schema Copy plus Tag" (SC $+\mathrm{T}$ ) model of memory for scripted as well as other types of schematic information. In addition to explaining variability in typicality, this model attempts to explain schematic memory as a function of the type of memory test given (recall vs. recognition) and the length of time between testings. No consideration is given to individual differences.

The results of the present study; nonetheless, clearly indicate that subject variables should not be ignored when formulating models of scriptinformation processing. Reflection-impulsivity may be only one of many such variables influencing schematic recall. Other possibilities may include field dependence-independence, arousal level, and cognitive set, to mention a few. It is therefore suggested that researchers in this area broaden the scope of variables that they are examining in order to arrive at a more comprehensive understanding of the dynamics of this particular memory process.

\section{REFERENCES}

Bellezza, F. S., \& Bower, G. H. (1982). Remembering script-based text. Poetics, 11, 1-23.

BOWER, G. H., BLACK, J. B., \& TURNER, T. J. (1979). Scripts in memory for text. Cognitive Psychology, 11, 177-220.

Graesser, A. C., \& NaKamura, G. V. (1982). The impact of a schema on comprehension and memory. In G. H. Bower (Ed.), The Psychology of Learning and Motivation (Vol. 16). New York: Academic Press.

KAGAN, J. (1965). Impulsive and reflective children: The significance of conceptual tempo. In J. D. Krumboltz (Ed.), Learning and the educational process. Chicago: Rand McNally.

KAGAN, J., \& KogAN, N. (1970). Individual variation in cognitive processes. In P. E. Mussen (Ed.) Carmichael's manual of child psychology (Vol. 1, 3rd ed.). New York: Wiley.

Messer, S. B. (1976). Reflection-impulsivity: A review. Psychological Bulletin, 83, 1026-1052.

Schank, R. C., \& Abelson, R. P. (1977). Scripts, plans, goals, and understanding. New Jersey: Erlbaum.

(Manuscript received for publication October 3, 1985.) 